Saudi Journal of Humanities and Social Sciences

Abbreviated Key Title: Saudi J Humanities Soc Sci

ISSN 2415-6256 (Print) | ISSN 2415-6248 (Online)

Scholars Middle East Publishers, Dubai, United Arab Emirates

Journal homepage: https://saudijournals.com

Original Research Article

\title{
Effect of Physical Activity on Perceived Stress, Sleep Quality and Subjective Happiness during Middle Age
}

Dr. Sukhminder Kaur ${ }^{1 *}$, Chitra Arora ${ }^{2}$, Simarjeet Kaur ${ }^{3}$

\author{
${ }^{1}$ Associate Professor, Department of Psychology, Punjabi University, Patiala, India \\ ${ }^{2}$ Research Scholar, Department of Psychology, Punjabi University, Patiala, India \\ ${ }^{3}$ Research Scholar, Department of Psychology, Punjabi University, Patiala, India
}

DOI: $10.36348 /$ sjhss.2020.v05i12.004

| Received: 21.11.2020 | Accepted: 03.12.2020 | Published: 20.12.2020

*Corresponding author: Dr. Sukhminder Kaur

\section{Abstract}

Physical activity has been considered as an effective strategy for both physiological and psychological benefits. Though its effects are well documented among adolescents and adults, but it has not been studied extensively in middle aged people. Therefore, the objective of the present study was to see the effect of physical activity on perceived stress, sleep quality and happiness among middle aged people. Total 455 participants (males $=197$, females=258) in the age range of 40-60 years were recruited for the present study. To assess the domains of physical activity, perceived stress, sleep quality and subjective happiness, Godin-Shephard Leisure Time Exercise Questionnaire (Godin, 1985), Perceived Stress Scale (Cohen et. al., 1983), Pittsburgh Sleep Quality Index (Buysse, et al., 1989) and Subjective Happiness Scale (Lyubomirsky \& Lepper, 1999) were used respectively. Obtained scores were subjected to two-way analysis of variance. Findings of the study revealed significant effect of physical activity on perceived stress $(\mathrm{F}=3.34 ; \mathrm{p}<0.05)$ and sleep quality $(\mathrm{F}=387.036 ; \mathrm{p}<0.01)$. But, physical activity did not produce significant effect on subjective happiness among male and female participants. The study indicates that physical activity plays a vital role in enhancing sleep quality and reducing perceived stress among middle-aged people. The significant implications have been discussed.

Keywords: Physical activity, Perceived stress, Sleep quality, Subjective happiness.

Copyright ( $\odot 2020$ The Author(s): This is an open-access article distributed under the terms of the Creative Commons Attribution 4.0 International License (CC BY-NC 4.0) which permits unrestricted use, distribution, and reproduction in any medium for non-commercial use provided the original author and source are credited.

\section{INTRODUCTION}

Middle age, a period of diversity is often portrayed as a time of crises. At this juncture of life, individuals juggle with many roles like parents, spouses, adult children and workers and make adjustments in multiple arenas. They also experience a range of expected events like children's departure, retirement and parents' death as well as unexpected life events like loss of spouse that may exacerbate strains produced by the multiple roles. Apart from this, they have a feeling that the peak years of life are passing and that the body is slowing down. Due to these modifications or ideas, middle aged people often experience stress, mood swings, insomnia, and irritability. Although such challenging experiences may provide a context for development to people [1] and an opportunity to adapt with their later life period [2], but exposure to such unavoidable events and expectations threaten their health status and functioning in varied areas of life. Empirical evidences indicate that frequency and nature of stressful events change with age. For example, young adults enter into new roles whereas middle aged people typically experience role changes and losses. It has been shown that perceived stress is highly prevalent during middle age, especially among females [3]. Since the appearance of covid-19, people are living with feelings of uncertainty, fears and a set of concerns associated with pandemic. Currently, the progressive return to the everyday life with preventive and safety measures has also increased the stress and anxiety levels. To deal with this kind of issues, physical activity is frequently endorsed as a strategy for improving physical and mental health of people. In order to prevent mental health problems associated with pandemic, World Health Organization has also placed emphasis on healthy life style through regular exercise, nutritious diet and good sleep. Hence, the present study focused on physical activity and its impact on perceived stress, sleep quality and subjective happiness among middle aged people.

Physical activity is a positive leisure activity. It refers to any bodily movement produced by skeletal muscles that results in energy expenditure [4]. It encompasses exercise as well as other activities 
undertaken while playing, working, carrying out household chores, travelling and engaging in recreational pursuits. All kinds of physical activities can be performed in a variety of intensities ranging between light, moderate and vigorous. As per WHO [5] recommendations, middle aged group require at least 150 minutes of moderate intensity activity throughout the week or at least 75 minutes of vigorous intensity physical activity throughout the week. Researches following these recommendations reveal that people who exercise with moderate intensity exhibit approximately half the amount of perceived stress as those who reported no exercise [6]. Moreover, in a five year longitudinal study of middle aged women, vigorous exercise was found to reduce perceived stress significantly in first year [7]. Similarly, higher physical activity, particularly aerobic activity has been found to be associated with lower levels of perceived stress [8, 9]. It has also been reported that people who exercise twice or thrice a week have been reported to exhibit a lower level of stress than those who exercise less frequently or who do not exercise at all [10].In researches, physical activity has been considered as a protective factor for chronic diseases like cardiovascular diseases [11, 12], cancer [13, 14, 15], diabetes [16, 17] and hypertension [18]. It has also been reported that regular physical activity helps in slowing down many age-related functional declines. It plays a vital role in reducing risk and improving a number of psychological parameters of performance [19] and acts as a buffer against stress [20]. Contrarily, researchers $[21,22]$ found non-significant effect of physical activity on psychological functioning. Physiologically, it improves the mental health of people by bumping up the production of neurotransmitters such as endorphin, serotonin which ease stress and improve the quality of sleep respectively and further, enhancing the overall quality of life and well-being. As an emerging body of research suggested that regular physical activity is a critical component of health that has many beneficial effects on physical and psychological well-being of people across the life span, the present study was an attempt to see the role of physical activity in stress management during middle age.

All individuals experience a certain amount of stress in their daily lives. A mounting body of research indicates that an appropriate proportion of stress drives us to achieve more in life, improves quality of life and generates positive impact on our psychological functioning. On the other hand, it has frequently been associated with a broad spectrum of adverse health outcomes and negative behaviours. Researchers [23] have reported that higher level of stress hinders to maintain a healthy life style and habits like eating a nutritious diet, getting good sleep and fostering positive interpersonal relationships. Accordingly, it gives rise to negative consequences such as anxiety, depression and aggression [24] which further influence the quality of life and physical health of the individual [25]. In this regard, Lazarus \& Folkman [26] states that person's circumstances exposes him or her to certain stressors that may tax or exceeds the resources which in turn threatens the health status and functioning of the person. They reveal that stress is the outcome of individual's appraisal of environmental events and coping with them. When a person perceives an event as stressful, he or she experiences negative effects [27, 28]. During middle adulthood period, people experience a diverse amount of stressors. Though these stressors do not lead stress individually, but the culmination of numerous stressors dictates a person to perceive the situation as stressful. In parallel to this, health related researches have shown that when the stressors are prolonged and intense, it leads to immense physiological, psychological problems and negative adjustments to social situations. Moreover, perceived stress is related with decrease in happiness [29]. Additionally, it was found that gender plays an important part in perceived stress. Men and women have different parameters by which they experience stressful circumstances. Men are more likely to list finances and work-related events as sources of their stress, whereas women were more likely to list family and health related stressors [30]. Generally, females are more affected by stressors [31]. Contrarily, some of the findings show that females displayed more optimism than men and have lower level of perceived stress compared to men [32]. However, studies by Donaldson, Prinstein, Danorsky and Spirito [33] revealed that there were no gender differences in coping with stress.

It is commonly validated that a normal restful sleep is vital for bodily processes, immune system and to meet demands and expectations of our daily life. However, whether we get an adequate amount of sleep is determined by our physiological as well as psychological state like how we feel. Researchers in this regard state that a maladaptive stress response implicates in poor sleep quality and quantity. Sleep quality refers to one's satisfaction to sleep experience, integrating aspects of sleep initiation, sleep maintenance and sleep quantity along with refreshment upon awakening [34]. People who lack satisfying and refreshing sleep experiences often report reduced alertness, poor cognitive performance $[35,36]$, obesity [37, 38], poor self-esteem [39], lowered optimism and sociability [40], negative moods and increased likelihood of stimulant use [41]. Moreover, insufficient sleep significantly impact women's routine life including her professional and societal roles [42]. In researches, such effects are found as significant factors that determine sleep quality and sleep patterns. In addition to this, age and gender, the non-modifiable factors also affect sleep quality. It has been consistently reported that poor sleep quality is a major problem among females. The National Sleep Foundation [43] indicated that women experience more sleep fragmentation and lower sleep quality than men. 
Recently, it has been reported that females tend to have poorer sleep quality in comparison to males [44, 45]. The reasons for these differences in sleep quality are due to differential lifestyle and socio demographic factors [46]. Throughout life women have to experience various hormonal and physical changes at the time of puberty, pregnancy and menopause. Nevertheless, National Sleep Foundation [47] recommended that working out regularly can promote better sleep as it raises body temperature a few degrees and when internal thermostat drops back to normal range, feelings of drowsiness get triggered and aid one drop off to sleep. Apart from this, exposure to natural light while exercising outdoors helps in establishing good sleepwake cycle. A study conducted by Yang et al., [48] indicated that participating in an exercise training programme has positive effects on sleep quality in middle-aged people. Contrarily, in a cross-sectional study conducted by Pengpid and Peltzer [49] there was no association found between vigorous physical activity and sleep quality.

Happiness is a fundamental indicator of good physical and mental health. Broadly, it describes positive experiences and includes cognitive appraisal of one's life, positive and negative emotions. According to Diener [50] these three components develop the overall perception of happiness. Lyubomirsky \& Lepper [51] emphasized on the subjective qualities of happiness. Following these approaches, researchers have found that happy people are more likely to be healthier, live longer, have better social relationships and are more productive at work. David Blanchflower and Andrew David Blanchflower and Andrew Oswald [52] stated that happiness is closely associated closely associated with well-being and tended to be relatively high at younger age, decreases in midlife and then rise again after about age 60. Further, Soergel [53] stated that women reach their minimum level of well-being around their mid-40s and men in their late 40 s or early $50 \mathrm{~s}$. It fluctuates due to increasing health problems, major adverse life changes associated with advancing age which exerts a negative impact on subjective wellbeing. Regarding gender, studies have shown that women have lower levels of subjective well-being than men due to disadvantages in income, social relationships and socioeconomic status [54]. Contradictory evidence suggests that men experience lower subjective well-being than women as women prefer a diverse range of activities from which they gain happiness. Additionally, men may be more prone to difficulties in developing and continuing intimate relationships which could protect them from low subjective well-being and negative mental health conditions [55]. Empirical evidences indicate the inverse relationship between psychological stress and well-being [56, 57]. As positive emotions and thoughts are core ingredients of happiness, it plays a buffering role against stress. Further, it has been considered that psychological health can be measured with two ends like psychological distress and psychological wellbeing [58]. It is thus conjectured that anything deviating from distress would contribute in well-being. Though various interventions such as meditation, biofeedback training, music therapy, yoga and exercise have examined this association, but a regular routine of exercise have yielded promising results. According to standard American and European recommendations [59] for good health, people who exercised for at least 30 minutes every day are more likely to consider themselves happy compared to people who do not involve in any exercise [60. Similarly, Downward and Dawson [61] showed that participation in moderateintensity activity significantly adds to happiness. However, Paluska and Schwenk [62] have found that too much activity or training can have negative impact on well-being.

Since there are controversial findings concerning the role of gender and physical activity on the management of psychological issues, the aim of present study was to analyse the influence of duration of physical activity on perceived stress, sleep quality and subjective well-being during middle age.

\section{HYPOTHESES}

1. Highly active individuals would be lower on perceived stress and better in sleep quality and higher on subjective happiness as compared to moderately active individuals or insufficiently active individuals.

2. Females would be higher on perceived stress, lower on sleep quality and subjective happiness as compared to males.

3. Highly active males would demonstrate lower perceived stress, better sleep quality and higher subjective happiness as compared to highly active females.

\section{METHOD \\ Sample}

The present study was comprised of 455 individuals ( $n=197$ males and $n=258$ females) in the age range of 40 to 60 years. The sample was drawn online from various states of India i.e. Punjab, Rajasthan, Karnataka, West Bengal, Madhya Pradesh and Uttar Pradesh. All the participants were graduate or above graduate and living in urban setup. From which 71.43 $\%$ people were working and $28.57 \%$ non-working. To establish the genuine responses only those subjects were included who were willing to participate in the study.

\section{Measures used present study \\ Godin-Shephard Leisure Time Exercise Questionnaire [63]}

Following measures were used to carry out the

This questionnaire was used to assess physical activity by a total weekly leisure activity score. The 
scale comprises of 3 items that inquire about the number of times one engages in mild, moderate, strenuous activity for more than 15 minutes in a given week during free time. The number of times one engages in these type of activities per week is multiplied by 3,5 and 9 respectively. The sum of these products is computed to obtain the total leisure time activity score. People having activity score of 24 units or more are classified as active, scores in the range of 14-23 are classified as moderately active and scores less than 14 indicate insufficiently active/sedentary individuals. The reliability of the scale was found to be 0.74 and the validity was found to be 0.24 .

\section{Perceived Stress Scale [64]}

The Perceived Stress Scale was used to measure the degrees to which situation in one's life are appraised as stressful. PSS-10 is a five point scale and composed of 10 items in which 4 positive items i.e. 4 , $5,7,8$ have reverse scoring that is 4 to 0 and rest of the items have scoring of 0 to 4 . The average score considered for the scale is 13 and higher score indicates higher stress. The scale has adequate internal consistency reliability $(\alpha=.78)$ and adequate convergent validity.

\section{Pittsburgh Sleep Quality Index [65]}

Pittsburgh sleep quality index a self-rated questionnaire to assess sleep quality and disturbances over a one month time interval. In scoring the PSQI, seven component scores are derived, each scored 0 (no difficulty) to 3 (severe difficulty). The component scores are summed to produce a global score (range 0 to 21). Higher scores indicate worse sleep quality. It differentiates "poor" from "good" sleep by measuring seven domains: subjective sleep quality, sleep latency, sleep duration, habitual sleep efficiency, and sleep disturbances, use of sleep medication, and daytime dysfunction over the last month. Scoring of the answers is based on a 0 to 3 scale, whereby 3 reflect the negative extreme on the Likert Scale. A global sum of "5" or greater indicates a "poor" sleeper. The score ranges from 0-21. Higher score indicates worse sleep quality. The Cronbach's $\alpha$ for PSQI is 0.83 indicating a high degree of internal homogeneity.

\section{Subjective Happiness Scale [66]}

A 4 items scale was used to measure subjective happiness variable in the present study. It is a 7-point likert scale in which item number 4 is reverse scored. For happiness score there is a need to compute the mean/average scores of each item together. The average score ranges from 4.5 and 5.5. The average score of students tends to be below five while working adults have an average score of 5.6. Higher score indicates happier people. People scored less than 4 needs to take professional help. The scale has excellent internal consistency ( $\alpha$ 's ranging from 0.79 to 0.94 ) and testretest reliability (ranging from 0.55 to 0.90 ).

\section{Personal Data Sheet}

For gathering demographic information, Personal Data Sheet was used including age, gender, occupational status and city of residence.

\section{Design \& Procedure}

Factorial design (2X3) with two levels of gender (male and female), three levels of physical activity (high activity, moderate activity and insufficient activity) was chosen for the present study. Total 455 individuals (males $=43.3 \%$ and females $=56.7 \%$ ) in the age range of $40-60$ years were selected from different states of India. Following snowball sampling principles, potential respondents were invited through a text message. As the data was collected using Google forms, the link was communicated through whats App and emails by the investigators. Before starting the questionnaires, the online survey included the brief description of the study, its aim and the declarations of anonymity and confidentiality. By ensuring confidentiality of participants' responses, they were informed about the significance and implications of study and consent was taken from them. Those who volunteered were enrolled in the study and were online administered standardized questionnaires like Perceived Stress Scale, Pittsburgh Sleep Quality Index, Subjective Happiness Scale and Physical Activity Questionnaire along with Personal Data Sheet for demographic details. A total of 615 subjects residing in urban areas completed the Google forms over a period of two weeks (from $18^{\text {th }}$ August to $3^{\text {rd }}$ September, 2020) when almost everything was getting reopened amid COVID-19 crises. Out of 615, data of 160 were excluded due to incomplete information. Then, the sample comprised of 455 Indian subjects. Obtained data was scored according to the guidelines provided in manuals and analysed statistically by using IBM SPSS statistics version 20.0.

\section{RESULTS AND DISCUSSION}

The main objective of the present investigation was to explore the effect of physical activity on perceived stress, sleep quality and subjective happiness of individuals. For this purpose, obtained scores were subjected to two-way analysis of variance and the results are presented in Table No.1 and Table No.2.

Further, it was observed that participants in the present study reported higher to moderate level of stress. According to available cut-off scores for perceived stress on average, individuals endorsed moderate level of perceived stress, and around $37 \%$ of the sample reported higher levels of stress. Further, middle aged individuals $34 \%$ self-reported poor sleep quality and $22 \%$ scored higher on subjective happiness scale. This suggests that participants of the study experienced both high levels of stress and poor sleep quality. Regarding physical activity, for high activity males $(77 \%)$ and females $(70 \%)$, for moderate activity males $(13 \%)$ and females $(12 \%)$ as well as for insufficient activity males $(10 \%)$ and females $(18 \%)$. It 
shows that males were more engaged in physical activity than females.

Table-1: Means \& Standard deviations for Perceived Stress and Sleep Quality and Subjective Happiness

\begin{tabular}{|c|c|c|c|c|c|}
\hline & \multicolumn{2}{|l|}{ Gender } & \multicolumn{3}{|c|}{ Physical Activity } \\
\hline & Male & Female & High Activity & $\begin{array}{l}\text { Moderate } \\
\text { Activity }\end{array}$ & $\begin{array}{l}\text { Insufficient } \\
\text { Activity }\end{array}$ \\
\hline $\begin{array}{l}\text { Perceived } \\
\text { Stress }\end{array}$ & $\begin{array}{l}\text { Mean }=16.15 \\
\{S D=6.86\}\end{array}$ & $\begin{array}{l}\text { Mean }=17.53 \\
\{S D=6.44\}\end{array}$ & $\begin{array}{l}\text { Mean }=16.58 \\
\{S D=6.60\}\end{array}$ & $\begin{array}{l}\text { Mean=17.56 } \\
\{\mathrm{SD}=6.71\}\end{array}$ & $\begin{array}{l}\text { Mean }=18.90 \\
\{\mathrm{SD}=6.84\}\end{array}$ \\
\hline Sleep Quality & $\begin{array}{l}\text { Mean }=4.50 \\
\{\mathrm{SD}=2.86\}\end{array}$ & $\begin{array}{l}\text { Mean }=6.86 \\
\{S D=7.91\}\end{array}$ & $\begin{array}{l}\text { Mean }=4.85 \\
\{S D=2.96\}\end{array}$ & $\begin{array}{l}\text { Mean=4.93 } \\
\{\mathrm{SD}=3.22\}\end{array}$ & $\begin{array}{l}\text { Mean=5.21 } \\
\{S D=3.32\}\end{array}$ \\
\hline $\begin{array}{l}\text { Subjective } \\
\text { Happiness }\end{array}$ & $\begin{array}{l}\text { Mean=20.31 } \\
\{\mathrm{SD}=4.30\}\end{array}$ & $\begin{array}{l}\text { Mean=19.87 } \\
\{\mathrm{SD}=4.20\}\end{array}$ & $\begin{array}{l}\text { Mean }=20.30 \\
\{S D=4.25\}\end{array}$ & $\begin{array}{l}\text { Mean=19.63 } \\
\{S D=4.24\}\end{array}$ & $\begin{array}{l}\text { Mean }=18.75 \\
\{S D=4.04\}\end{array}$ \\
\hline
\end{tabular}

Table-2: Summary of the ANOVA (2x3) for the effect of Gender and Physical activity on Perceived Stress and Sleep Quality and Subjective Happiness

\begin{tabular}{|c|c|c|c|c|c|c|}
\hline Variables & Source of Variation & SS & df & MS & $\mathbf{F}$ & \\
\hline \multirow{4}{*}{$\begin{array}{l}\text { Perceived } \\
\text { Stress }\end{array}$} & Gender (A) & 185.367 & 1 & 185.367 & $4.286^{*}$ & .039 \\
\hline & Physical activity (B) & 288.334 & 2 & 144.167 & $3.333^{*}$ & .037 \\
\hline & $\mathrm{AxB}$ & 285.284 & 2 & 142.642 & $3.298 *$ & .038 \\
\hline & Error & 19418.370 & 449 & 43.248 & & \\
\hline \multirow[t]{4}{*}{ Sleep Quality } & Gender (A) & 5651.217 & 1 & 5651.217 & $593.005 * *$ & .000 \\
\hline & Physical activity (B) & 7376.746 & 2 & 3688.373 & $387.036 * *$ & .000 \\
\hline & $\mathrm{AxB}$ & 7446.737 & 2 & 3723.369 & $390.708 * *$ & .000 \\
\hline & Error & 4278.882 & 449 & 9.530 & & \\
\hline \multirow{4}{*}{$\begin{array}{l}\text { Subjective } \\
\text { Happiness }\end{array}$} & Gender (A) & 19.703 & 1 & 19.703 & 1.093 & .296 \\
\hline & Physical Activity(B) & 93.068 & 2 & 46.534 & 2.582 & .077 \\
\hline & $\mathrm{AxB}$ & 2.574 & 2 & 1.287 & .071 & .931 \\
\hline & Error & 8091.274 & 449 & 18.021 & & \\
\hline
\end{tabular}

Findings of the present study revealed the significant effect of physical activity (high activity, moderate activity, insufficient activity) on perceived stress $(\mathrm{F}=3.34 ; \mathrm{p}<0.05)$. It indicates that individuals who are highly active $(\mathrm{M}=16.58)$ were lower on perceived stress as compared to individuals who are moderately active $(\mathrm{M}=17.56)$ or individuals who are insufficiently active $(M=18.90)$. Further, in case of sleep quality, the results demonstrate a beneficial effect of physical activity on sleep quality $(\mathrm{F}=387.036$; $\mathrm{p}<0.01)$. It was found that individuals who are highly active $(M=4.85)$ have good sleep quality as compared to individuals who are moderately active $(\mathrm{M}=4.93)$ or individuals who are insufficiently active $(\mathrm{M}=5.21)$. Thus proving the hypothesis, the results revealed that individuals who engage in physical activity regularly appraise the situation less stressful and experience good sleep quality. The findings get support from previous correlational [67], experimental [68] and quasi experimental studies $[69,70]$ in which the similar effect was observed that with increase in physical activity stress level decreases. In the same context, Holland [71] stated that as physical activity improves resistance that may reduce individuals' susceptibility to stress. Maher et al. [72] also reported that engaging in physical activity 5-7 times per week has shown greater reductions in perceived stress levels and in turn is associated with better physical health [73, 74]. Interestingly, taking part in regular physical activity for even less than 15 minutes per day can provide health benefits [75]. Regarding sleep quality, Badicu [76] stated that physical activity is beneficial for the body, and can improve the quality and quantity of sleep, if carried out systematically and continuously. Similarly, a meta-analysis of six studies found that exercise training resulted in modest improvements in subjective sleep quality in middle-to older-aged adults with sleep problems [48]. Wang and Boros [77] found that moderate physical activity seems to be more effective than vigorous physical activity in improving sleep quality. Moreover, it was found that moderate physical exercise is beneficial to sleep quality in both young and old populations. Such improvements can be ascribed to physiological basis of physical activity. It has been shown that physical activity activates the release of endorphins, noradrenaline and feel good neurotransmitters that generates 'exercise-induced euphoria' and consequently the exerciser. Therefore, regular physical activity proved a very effective technique for managing stress and improving sleep quality during middle age. However, physical activity did not produce significant effect on subjective happiness among male and female participants of the study which failed to confirm the hypothesis that 
individuals who are involved in high physical activity levels would be higher on subjective happiness. Further, gender also did not achieve the level of significance. Contrarily, prior researches have shown that physical activity and happiness are interrelated. In researches, physical activity appears to be closely associated with the positive affective dimension of happiness that includes joy, excitement and confidence [78, 79]. Performing regular exercise regularly could promote health and subjective well-being [80, 81] and active participation of young adults in physical activity also had higher levels of happiness. The reason for the contrasting result could be the tendency of participants to feel compelled to take part in physical activity rather than choosing to perform physical activity as part of healthy lifestyle, which can result in weak relationship with subjective happiness. During middle age, people engage themselves in exercising behaviours temporarily especially women to cope with the health related challenges and on the medical practitioners' suggestion that 'exercise is good for you.' Apart from this, certain other factors such as social network, environment, culture and social support play an influential role and are related to the physical activity and mental health relationship [82]. Regarding gender, there are several studies that had not found significant differences in subjective happiness among adult male and female participants [83-85]. Although, the findings did not reveal significant results, it can be stated that physical activity might help participants to maintain positive psychological state for adding exercise to their life style.

Findings of the present investigation also highlighted that gender differed significantly on perceived stress $(\mathrm{F}=4.286 ; \mathrm{p}<0.05)$ and sleep quality $(\mathrm{F}=593.005 ; \mathrm{p}<0.01)$. The results indicated that females were higher on perceived stress and had poor sleep quality as compared to males. Researches carried out in the past lend support to the findings by stating that men engaged themselves more in physical activity [86] and were less stressed [87] than women. In the same vein, Matud [88] reported that stressful events experienced by men and women were also different where women reported more family and health related events whereas men reported events related to work and finance. Moreover, women need to make adjustments in multiple arenas like the inherent pressure of contributing to the financial means, fulfilling their role as mothers and homemakers etc. while maintaining work-life balance, they deal with everyday stressors like dealing with traffic during a commute, or changing work hours [89, 90]. Although not evaluated as challenging, these have a cumulative effect and contribute to, or are associated with, the outcomes of major life events [91]. Therefore, such differences can be attributed to the stress of motherhood along with other family responsibilities that impact their mental health to a very large extent. Bei,et. al. [92] also considered multiple factors across a woman's lifespan like age- related physiological changes such as more fluctuation in hormone levels, psychosocial factors, and physical and mental health conditions play a major role in the complaints of poor sleep in women. Hence, they experience higher stress which in turn influences their sleep quantity and quality.

Findings of the present investigation revealed a significant interaction effect of gender and physical activity on perceived stress $(\mathrm{F}=3.298 ; \mathrm{p}<0.05)$ and sleep quality $(\mathrm{F}=390.708 ; \mathrm{p}<0.01)$. This means that the effectiveness of a particular level of physical activity depends on gender in creating significant impact on perceived stress and quality of sleep. It was found that highly active males were lower on perceived stress $(\mathrm{M}=15.92)$ and had better sleep quality $(\mathrm{M}=4.28)$ as compared to highly active females $(\mathrm{M}=16.94, \mathrm{M}=5.25)$. It indicates that men benefitted more from physical activity in managing their stress levels and experiencing better sleep quality than women. At the same time, Fvalue for subjective happiness did not achieve the level of significance. Support for the present findings can be derived from "mastery hypothesis" which states that physical activity provides a sense of accomplishment resulting into improvement in mood [93]. Moreover, it is an effective way to distract from the stressful situations. This result could be due to the reason that males and females face differential level of stress and females perceive greater psychological stress than men. Apart from this, women may require more activity level and different type of activity than men in order to lessen stress. Campbell, et al. [87] found that women reported the need to increase activity levels in order to reduce their perceived level of stress. Koo and Kim [94] revealed in their research that for women with activity limitations, flexibility exercise is likely to lower the perceived stress level than other types of exercise. Hence, the duration as well as type of physical activity for a particular gender must be taken into consideration in order to reduce perceived stress and improve quality of sleep.

\section{CONCLUSION}

Taken all together, results of the present research and prior researches that were discussed come up with significant insights on the topic. Although physical activity was not used as a coping technique in the present study, but the obtained findings add to the body of research. The findings of the present study have main implications for the counsellors, medical professionals, health care providers and the general public alike. The findings provide evidence for the effect of physical activity in reducing stress and improving sleep quality. Since the emergence of the covid-19 have changed daily life both from a personal, social or professional perspectives, such improvements are important for dealing with the pandemic related challenges more effectively. Hence, the positive effects of regular physical activity on psychological issues should be publicized. It was suggested that both men and women experienced lower stress and better sleep 
quality when they participated in physical activity for more than 150 minutes in a week, and men seemed to benefit more. In this regard, women should be encouraged to indulge themselves in regular exercise for longer time. Though the finding has led to important and useful conclusion, but additional research is needed. Simple effects need to be explored to understand the nature of the interaction effects. Moreover, the present study did not include background information regarding medication and the possibility of already existing psychological disturbances such as anxiety and depression with its many degrees, multiple confounding effects could influence the results. Future studies can explore this area by controlling psychological instabilities.

\section{REFERENCES}

1. Aldwin, C. M. (1994). Stress, coping, and development: An integrative perspective. Guilford Press.

2. Magai, C., \& Halpern, B. (2001). Emotional development during the middle years. In M. E. Lachman (Ed.), Wiley series on adulthood and aging. Handbook of midlife development (p. 310344). John Wiley \& Sons, Inc.

3. Cuadros, J.L., Fernández-Alonso, A.M., CuadrosCelorrio, A.M., Fernández-Luzón, N., GuadixPeinado, M.J., Cid-Martín, N., Chedraui, P., \& Pérez-López, F.R. (2012). MenopAuse RIsk Assessment (MARIA) Research Group, Perceived stress, insomnia and related factors in women around the menopause. Maturitas, 72(4), 367-372.

4. Caspersen, C.J., Powell, K.E., \& Christenson, G.M. (1985). Physical activity, exercise, and physical fitness: Definitions and distinctions for healthrelated research. Public Health Reports, 100(2), 126-131.

5. Global Recommendations on Physical Activity for Health. (2010). Geneva: World Health Organisation.

6. Aldana, S.G., Sutton, L.D., Jacobson, B.H., \& Quirk, M.G. (1996). Relationships between leisure time physical activity and perceived stress. Perceptual and Motor Skills, 82(1), 315-321.

7. Guérin, E., Biagé, A., Goldfield, G., \& Prud'homme, D. (2017). Physical activity and perceptions of stress during the menopause transition: A longitudinal study. Journal of Health Psychology, 24(6), 799-811.

8. Štefan, L., Sporiš, G., \& Krističević, T. (2018). Are lower levels of physical activity and self-rated fitness associated with higher levels of psychological distress in Croatian young adults? A cross-sectional study. PeerJ, 6(4), 1-9.

9. Felez-Nobrega, M., Bort-Roig, J., Briones, L., Sanchez-Niubo, A., Koyanagi, A., Puigoriol, E., \& Puig-Ribera, A. (2020). Self-reported and activPALTM-monitored physical activity and sedentary behaviour in college students: Not all sitting behaviours are linked to perceived stress and anxiety. Journal of Sports Sciences, 38(13), 15661574.

10. Hassmén, P., Koivula, N., \& Uutela, A. (2000). Physical exercise and psychological well-being: A population study in Finland. Preventive Medicine, $30,17-25$.

11. Thompson, P.D., Buchner, D., Pina, I.L., Balady, G.J., Williams, M.A., Marcus, B.H., Berra, K., Blair, S.N., Costa, F., Franklin, B., Fletcher, G.F., Gordon, N.F., Pate, R.R., Rodriguez, B.L., Yancey, A.K., \& Wenger, N.K. (2003). Exercise and physical activity in the prevention and treatment of atherosclerotic cardiovascular disease: A statement from the Council on Clinical Cardiology (Subcommittee on Exercise, Rehabilitation, and Prevention) and the Council on Nutrition, Physical Activity, and Metabolism (Subcommittee on Physical Activity). Circulation, 107(24), 3109 3116.

12. Li, J., \& Siegrist, J. (2012). Physical activity and risk of cardiovascular disease - A meta-analysis of prospective cohort studies. International Journal of Environmental Research and Public Health, 9(2), 391-407.

13. Moore, M.A., Park, C.B., \& Tsuda, H.T. (1998). Physical exercise: A pillar for cancer prevention. European Journal of Cancer Prevention, 7, 177193.

14. Kiningham, R.B. (1998). Physical activity and the primary prevention of cancer. Prim Care, 25(2), 515-536.

15. Friedenreich, C.M., Neilson, H.K., \& Lynch, B.M. (2010). State of the epidemiological evidence on physical activity and cancer prevention. European Journal of Cancer, 46(14), 2593-604.

16. Cohen, N.D., Dunstan, D.W., Robinson, C., Vulikh, E., Zimmet, P.Z., \& Shaw, J.E. (2008). Improved endothelial function following a 14month resistance exercise training program in adults with type 2 diabetes. Diabetes research and clinical practice, 79(3), 405-411.

17. Ghosh, S., Khazaei, M., Moien-Afshari, F., Ang, L.S., Granville, D.J., \& Verchere, C.B. (2009). Moderate exercise attenuates caspase-3 activity, oxidative stress, and inhibits progression of diabetic renal disease in $d b / d b$ mice. American Journal of Physiology - Renal Physiology, 296(4), F700-F708.

18. Cornelissen, V.A., \& Smart, N.A. (2013). Exercise training for blood pressure: A systematic review and meta-analysis. Journal of American Heart Association, 2(1): e004473.

19. Donnelly, J. E., Hillman, C. H., Castelli, D., Etnier, J. L., Lee, S., Tomporowski, P., Lambourne, K., \& Szabo-Reed, A. N. (2016). Physical activity, fitness, cognitive function, and academic achievement in children: A systematic review. Medicine and Science in Sports and Exercise, 48(6), 1223-1224. 
20. Tucker, L. A., Cole, G. E., \& Friedman, G. M. (1986). Physical fitness: A buffer against stress. Perceptual and Motor Skills, 63(2), 955-961.

21. Nguyen-Michel,S.T., Unger,J.B., Hamilton,J., \& Spruijt-Metz, D. (2016). Associations between physical activity and perceived stress/hassles in college students. Stress and Health, 22, 179-188.

22. Moksnes, U.K., Moljord, I.E.O, Espnes, G.A., \& Byrne, D.G. (2010). Leisure time physical activity does not moderate the relationship between stress and psychological functioning in Norwegian adolescents. Mental Health and Physical Activity, 3(1), 17-22.

23. Britz, J., \& Pappas, E. (2010). Sources and outlets of stress among university students: Correlations between stress and unhealthy habits. Undergraduate Research Journal for the Human Sciences 9(1).

24. Jaser, S.S., Langrock, A.M., Keller, G., Merchant, M.J., Benson, M.A., Reeslund, K., \& Compas, B.E. (2005). Coping with the stress of parental depression II: Adolescent and parent reports of coping and adjustment. Journal of Clinical Child and Adolescent Psychology, 34, 193-205.

25. Leonard, B.E. (2010). The concept of depression as a dysfunction of the immune system. Current Immunology Reviews, 6(3), 205-212.

26. Lazarus, R. S., \& Folkman, S. (1984). Stress, Appraisal, and Coping. New York: Springer.

27. Nolen-Hoeksema, S., \& Morrow, J. (1991). A prospective study of depression and posttraumatic stress symptoms after a natural disaster: The 1989 Loma Prieta earthquake. Journal of Personality and Social Psychology, 61(1), 115-121.

28. Shaham, Y., Singer, J., \& Schaeffer, M. (1992). Stability/Instability of Cognitive Strategies Across Tasks Determine Whether Stress Will Affect Judgmental Processes. Journal of Applied Psychology, 22(9), 691-713.

29. Schiffrin, H. H., \& Nelson, S. K. (2010). Stressed and happy? Investigating the relationship between happiness and perceived stress. Journal of Happiness Studies: An Interdisciplinary Forum on Subjective Well-Being, 11(1), 33-39.

30. Anbumalar, C., Dorathy, A. P., Jaswanti, V. P., Priya, D., \& Reniangelin, D. (2017). Gender Differences in Perceived Stress levels and Coping Strategies among College Students. International Journal of Indian Psychology, 4(4).

31. Feizi, A., Aliyari, R., \& Roohafza, H. (2012). Association of perceived stress with stressful life events, lifestyle and sociodemographic factors: A large-scale community-based study using logistic quantile regression. Computational and Mathematical Methods in Medicine, 2012(4): 151865.

32. Sitz, E. H., \& Poche, N. (2006). Gender Differences in Relationship between Optimism and Perceived Stress. National Undergraduate
Research Clearinghouse. Retrieved from http:www.webclearinghousenet/volume/.

33. Donaldson, D., Prinstein, M.J., Danovsky, M., \& Spirito; A. (2000). A pattern of children's coping with life stress: Implications for clinicians. American Journal of Orthopsychiatry, 70(3), 351359.

34. Gellman, M.D., \& Turner, J.R. (Eds.). (2013). Encyclopaedia of behavioral medicine. New York, NY: Springer.

35. Pilcher, J. J., \& Huffcutt, A. J. (1996). Effects of sleep deprivation on performance: A meta-analysis. Sleep. Journal of Sleep Research \& Sleep Medicine, 19(4), 318-326.

36. Philibert, I. (2005). Sleep loss and performance in residents and nonphysicians: A meta-analytic examination. Sleep, 28, 1393-1402.

37. Morselli, L., Leproult, R., Balbo, M., \& Spiegel, K. (2010). Role of sleep duration in the regulation of glucose metabolism and appetite. Best Practice and Research Clinical Endocrinology Metabolism, 24(5), 687-702.

38. Knutson, K.L. (2012). Does inadequate sleep play a role in vulnerability to obesity? American Journal of Human Biology, 24(3), 361-371.

39. Boryana, S. (2015). Associations between poor sleep quality and insomnia symptoms in relation to self-esteem and self-efficacy. BPS Scottish Branch Undergraduate Conference.

40. Haack, M., \& Mullington, J.M. (2005). Sustained sleep restriction reduces emotional and physical well-being. Pain, 119(1-3), 56-64.

41. Steptoe, A., Peacey, V., \& Wardle, J. (2006). Sleep Duration and Health in Young Adults. Arch Intern Med, 166(16), 1689- 1693.

42. Lee, K.A., \& Kryger, M.H. (2008). Women and sleep. Journal of Women's Health (Larchmt), 17(7), 1189-90.

43. National Sleep Foundation. (2005). Sleep in America poll. Retrieved from: https://www.sleepfoundation.org/articles/womenand-sleep.

44. Silva, M., Chaves, C., Duarte, J., Amaral, O., \& Ferreira, M. (2016). Sleep Quality Determinants among Nursing Students. Procedia - Social and Behavioral Sciences, 217, 999-1007).

45. Tang, J., Liao, Y., Kelly, B.C., Xie, L., Xiang, Y.T., Qi, C., Pan, C., Hao, W., Liu, T., Zhang, F., \& Chen, X. (2017). Gender and Regional Differences in Sleep Quality and Insomnia: A General Population-based Study in Hunan Province of China. Scientific Reports, 7, 43690.

46. Fatima, Y., Doi, S.A.R., Najman, J.M., \& Mamun, A.A. (2016). Exploring gender difference in sleep quality of young adults: Findings from a large population study. Clinical Medicine \& Research, 14(3-4), 138-144.

47. The National Sleep Foundation. (2019). Does exercise help or hurt sleep? Available from: 
https:/www.sleep.org/articles/does-exercise-helpor-hurt-sleep/.

48. Yang, P.Y., Ho, K.H., Chen, H.C., \& Chien, M.Y. (2012). Exercise training improves sleep quality in middle-aged and older adults with sleep problems: A systematic review. Journal of Physiotherapy, 58(3), 157-63.

49. Pengpid, S., \& Peltzer, K. (2018). Vigorous physical activity, perceived stress, sleep and mental health among university students from 23 low- and middle-income countries. International Journal of Adolescent Medicine and Health, 32(2).

50. Diener, E. (2000). Subjective well-being: The science of happiness and a proposal for a national index. American Psychologist, 55(1), 34-43.

51. Lyubomirsky, S., \& Lepper, H. S. (1999). A measure of subjective happiness: Preliminary reliability and construct validation. Social Indicators Research, 46(2), 137-155.

52. Blanchflower, D. G., \& Oswald, A. J. (2008). Is well-being U-shaped over the life cycle? Social Science \& Medicine, Elsevier, 66(8), 1733-1749.

53. Soergel, A. (2017). Happiness is a U and middle age is depressing. US News and World Report.

54. Pinquart, M., \& Sorensen, S. (2001). Gender differences in self-concept and psychological wellbeing in old age: A meta-analysis. Journals of Gerontology, 56B (4), 195-213.

55. Zebhauser, A., Hofmann-Xu, L., Baumert, J., Häfner, S., Lacruz, M.E., Emeny, R.T., Döring, A., Grill, E., Huber, D., Peters, A., \& Ladwig, K.H. (2013). How much does it hurt to be lonely? Mental and physical differences between older men and women in the KORA-Age Study. International Journal of Geriatric Psychiatry, 29(3), 245-52.

56. Sugiura, G., Shinada, K., \& Kawaguchi, Y. (2005). Psychological well-being and perceptions of stress amongst Japanese dental students. European Journal of Dental Education, 9(1), 17-25.

57. Clemente, M., Hezomi, H., Allahverdipour, H., Jafarabadi, M.A., \& Safaian, A. (2016). Stress and Psychological Well-being: An Explanatory Study of the Iranian Female Adolescents. Journal of Child and Adolescent Behavior, 4, 282.

58. Miner, Jatha, M. (2003). The Effects of Physical Activity and Exercise on Well-being. The Review: A Journal of Undergraduate Student Research, 6, 26-35.

59. Pate, R.R., Pratt, M., Blair, S.N., Haskell, W.L., Macera, C.A., Bouchard, C., Buchner, D., Ettinger, W., Heath, G.W., King, A.C., Kriska, A., Leon, A.S., Marcus, B.H., Morris, J., Paffenbarger, R.S., Patrick, K., Pollock, M.L., Rippe, J.M., Sallis, J., \& Wilmore, J.H. (1995). Physical Activity and Public health. A recommendation from the Centers for Disease Control and Prevention and the American College of Sports Medicine, 273, 402-407.

60. Zhang, Z., \& Chen, W. (2019). A Systematic Review of the Relationship between Physical
Activity and Happiness. Journal of Happiness Studies, 20, 1305-1322.

61. Downward, P., \& Dawson, P. (2016). Is it pleasure or health from leisure that we benefit from most? An analysis of well-being alternatives and implications for policy. Social Indicators Research, 126(1), 443-465.

62. Paluska, S.A., Schwenk, T.L. (2000). Physical activity and mental health: Current concepts. Sports Medicine, 29(3), 167-80.

63. Godin, G., \& Shephard, R.J. (1985). A simple method to assess exercise behavior in the community. Canadian Journal of Applied Sport Sciences, 10(3), 141-146.

64. Cohen, S., Kamarck, T., \& Mermelstein, R. (1983). A global measure of perceived stress. Journal of Health and Social Behavior, 24(4), 385-396.

65. Buysse, D.J., Reynolds, C.F., Monk, T.H., Berman, S.R. \& Kupfer, D.J. (1989). The Pittsburgh Sleep Quality Index: A new instrument for psychiatric practice and research. Psychiatry Research, 28(2), 193-213.

66. Lyubomirsky, S., \& Lepper, H. (1999). A measure of subjective happiness: Preliminary reliability and construct validation. Social Indicators Research, 46, $137-155$.

67. Can, S. (2019). The determining of Relationship between Physical Activity and Perceived Stress Level in Security Service Employees. Journal of Education and Training Studies, 7(1), 149

68. Calfas, K., \& Taylor, W. (1994). Effects of Physical Activity on Psychological Variables in Adolescents. Pediatric Exercise Science, 6, 406423.

69. Schnohr, P., Kristensen, T.S., Prescott, E. \& Scharling, H. (2005). Stress and life dissatisfaction are inversely associated with jogging and other types of physical activity in leisure time--The Copenhagen City Heart Study. Scandinavian Journal of Medicine and Science in Sports, 15(2), 107-12.

70. Salmon, P. (2001). Effects of physical exercise on anxiety, depression, and sensitivity to stress: A unifying theory. Clinical Psychology Review, 21(1), 33-61.

71. Holland, J. L. (1997). Making vocational choices: A theory of vocational personalities and work environments ( $3^{\text {rd }}$ ed.). Psychological Assessment Resources.

72. Maher, J.P., Doerksen, S.E., Elavsky, S., Hyde, A.L., Pincus, A.L., Ram, N., \& Conroy, D.E. (2013). A daily analysis of physical activity and satisfaction with life in emerging adults. Health Psychology, 32(6), 647-56.

73. Haskell, W. L., Lee, I. M., Pate, R. R., Powell, K. E., Blair, S. N., Franklin, B. A. \& Bauman, B.A. (2007). Physical Activity And Public Health: Updated Recommendation For Adults From The American College of Sports Medicine and the 
American Heart Association. Circulation, 116(9), 1081-1093.

74. Cohen, S., Janicki-Deverts, D., \& Miller, G. E. (2007). Psychological stress and disease. Journal of the American Medical Association, 298, 16851687.

75. Richardson, N. (2014). The effects of physical activity on perceived stress, anxiety and life satisfaction. Dublin Business School, School of Arts, Dublin.

76. Badicu, G. (2018). Physical Activity and Sleep Quality in Students of the Faculty of Physical Education and Sport of Braşov, Romania. Sustainability, 10(7), 1-10.

77. Wang, F., \& Boros, S. (2019). The effect of physical activity on sleep quality: A systematic review. European Journal of Physiotherapy. DOI: 10.1080/21679169.2019.1623314

78. Chyi, H., \& Mao, S. (2012). The determinants of happiness of China's elderly population. Journal of Happiness Studies, 13(1), 167-185.

79. Ferrer-i-Carbonell, A., \& Frijters, P. (2004). How important is methodology for the estimates of the determinants of happiness? The Economic Journal, 114(497), 641-659.

80. Scully, D., Kremer, J., Meade, M.M., Graham, R., \& Dudgeon, K. (1998). Physical exercise and psychological well-being: A critical review. British Journal of Sports Medicine, 32(2), 111-120.

81. Melzer, K., Kayser, B., \& Pichard, C. (2004). Physical activity: The health benefits outweigh the risks. Current Opinion in Clinical Nutrition and Metabolic Care, 7(6), 641-647.

82. Crone, D., Smith, A., \& Gough, B. (2005). "I feel totally alive, totally happy and totally at one": A psycho-social explanation of the physical activity and mental health relationship from the experiences of participants on exercise referral schemes. Health Education Research, 20(5), 600-611.

83. Francis, L. J. (1998). Happiness is a thing called stable extroversion: A further examination of the relationship between the Oxford Happiness Inventory and Eysenck's dimensional model of personality and gender. Personality and Individual Differences, 26, 5-11.

84. Kousha, M., \& Mohseni, N. (2000). Are Iranians Happy? A Comparative Study between Iran and the United States. Social Indicators Research, 52, 259289.

85. Mahon, E. N., \& Yarskei, A. (2005). Happiness as Related to Gender and Health in Early Adolescents. Clinical Nursing Research, 14, 175-190.

86. National Center for Health Statistics. 1997 National Health Interview Survey (NHIS). Public Use Data Release. NHIS Survey Description. ftp://ftp.cdc.gov/pub/ Health_Statistics/NCHS/ Dataset_Documentation/NHIS/1997/ srvydesc.pdf.

87. Campbell, R.L., Svenson, L.W., \& Jarvis, G.K. (1992). Perceived level of stress among university undergraduate students in Edmonton, Canada. Perceptual and Motor Skills, 75(2):552-554.

88. Matud, M.P. (2014). Gender differences in stress and coping styles. Personality and Individual Differences, 37(7), 1401-1415.

89. Gentry, L., Chung, J., Aung, N., Keller, S., Heinrich, K., \& Maddock, J. (2007) Gender Differences in Stress and Coping among Adults Living in Hawaii. California Journal of Health Promotion, 5(2), 89-102.

90. Rehman, S. (2015). Stress causing factors among women and strategies to cope up. Pacific Business Review International, 8(1), 11-18.

91. Sievert, L.L., Jaff, N., \& Woods, N.F. (2018). Stress and midlife women's health. Women's Midlife Health, 4, 4.

92. Bei, B., Coo, S., Baker, F.C., \& Trinder, J. (2015). Sleep in Women: A Review. Australian Psychologist, 50(1).

93. Carmack, C. L., de Moor, C., Boudreaux, E., Amaral-Melendez, M., \& Brantley, P. J. (1999). Aerobic fitness and leisure physical activity as moderators of the stress-illness relation. Annals of Behavioral Medicine, 21, 251-257.

94. Koo, K. M., \& Kim, C. J. (2018). The effect of the type of physical activity on the perceived stress level in people with activity limitations. Journal of Exercise Rehabilitation, 14(3), 361-366. 